\title{
NON-PSYCHIATRY CONSULTANT'S ATTITUDE TOWARDS PSYCHIATRY : A STUDY FROM UNIVERSAL COLLEGE OF MEDICAL SCIENCES, NEPAL
}

\author{
Subedi S. ${ }^{1}$, Aich T.K. ${ }^{2}$, Shah S. ${ }^{3}$, Thapa D.K. ${ }^{4}$
}

\section{ABSTRACT}

INTRODUCTION: Mental Health has been hidden behind the curtain of stigma and discrimination for a long time. Not only the mentally ill, even the mental health professionals are stigmatized. The medical professional's attitude to psychiatry appear to be negative, although the data are dated. Attitude of non-psychiatry consultants towards psychiatry may affect their ability to promote psychiatry as a discipline. The main aim of this study is to study the non-psychiatry consultants' attitude towards psychiatry.

METHODS: It is a hospital based cross-sectional descriptive study of 30 non-psychiatry consultants working in Universal College of Medical Sciences Teaching Hospital, Bhairahawa, Nepal. ATP-30 self report questionnaire was used to collect the data.

RESULTS: Majority of the subjects were male. About $69 \%$ of the consultants didn't have any exposure in the psychiatry. However, majority of the consultants had positive attitude towards psychiatry. The mean score for ATP-30 was 110.03.

CONCLUSION: Majority of the consultants had positive attitude towards psychiatry. However some erroneous beliefs are still prevalent among the consultants. The attitude of non-psychiatry consultants directly/indirectly affects the development of psychiatry as a discipline. Further studies of such kind can help to determine whether changes in attitudes towards psychiatry are needed among the non-psychiatry consultants.

1. Assistant Professor, Department of Psychiatry, Universal College of Medical Sciences \& Teaching Hospital, Bhairahawa, Nepal

2. Professor \& Head, Department of Psychiatry, Universal College of Medical Sciences \& Teaching Hospital, Bhairahawa, Nepal

3. Post Graduate Resident, Department of Psychiatry, Universal College of Medical Sciences \& Teaching Hospital, Bhairahawa, Nepal

4. Assistant Professor, Department of Psychiatry, Gandaki Medical College, Pokhara, Nepal

\author{
For correspondence \\ Dr. Sandip Subedi, M.D., \\ Department of Psychiatry, \\ Universal College of Medical Sciences \& Teaching Hospital, \\ Bhairahawa, Nepal \\ E-mail: sandipsubedi@hotmail.com
}




\section{INTRODUCTION}

Prevalence of mental illness in Nepal is about $15 \%$. ${ }^{1}$ Out of the total patients visiting any OPDs, $21-26 \%$ are suffering from some kind of mental illness. ${ }^{2}$ However, total number of patients visiting psychiatry OPDs for treatment is significantly lower than expected. According to the WHO report, psychiatric disorders are now amongthe top ten causes of economic burden of disease while depression is second in the list. ${ }^{3}$ Inspite of such a great scope, researches have shown a low level of preference for psychiatry as a speciality by medical students. ${ }^{4}$ Only $4-5 \%$ of UK graduates make psychiatry as their career choice currently. ${ }^{5}$ This has resulted in consistently lower number of practicing psychiatrist in the world inspite of the growing demand. It could be because of two reasons, firstly because of medical students misperceptions about psychiatry even before they begin medical school $^{6}$ and secondly, low status when compared with other specialties; seemingly less scientific, stigma, lower consideration among peers, lower financial benefits, and 'bad-mouthing' by medical specialists from other fields. ${ }^{7-9}$ The medical professional's attitude to psychiatry appears to be negative, although the data are dated..$^{10}$ Attitude of non-psychiatry consultants towards psychiatry may affect their ability to promote psychiatry as a discipline. Attitude is defined by Rezler as "an emotionally linked, learnt belief around an object or situation predisposing one to respond in some preferential manner." $A$ Attitudes are major determinants of behaviour ${ }^{12}$, in this regard if we can manipulate the consultants and the future consultants' attitude in a positive way, it might help to encourage students to choose psychiatric as a future career and also promote psychiatry as a discipline.

There is very little in the current world literature with regard to the non-psychiatry consultants' attitude towards psychiatry and none such literature in a developing country like Nepal.

\section{AIMAND OBJECTIVE}

The primary aim of this study was to know about nonpsychiatry consultants' attitude towards psychiatry.

\section{METHODOLOGY}

The ethical approval was obtained from the ethical committee before starting the study. Strict confidentiality of information was maintained and the data was used for research purpose only.

\section{Setting}

The study was conducted at Universal College of Medical Sciences-Teaching Hospital(UCMS-TH), Bhairahawa, Nepal. It is a 750 bedded general hospital. It has a well established psychiatry department with 70 in-patient beds. It is one of the largest mental health facility in the country. The department is training undergraduates from last 14 years and Post-graduates from last four years.

\section{Participants}

Participants were the non-psychiatry consultants' of all the clinical departments working in the UCMS-TH fulfilling the inclusion criteria and exclusion criteria.

\section{Instruments}

A brief demographic and career was designed to obtain the data about age, sex, current designation, total experience as consultant and experience in psychiatry

Attitude to psychiatry questionnaire (ATP-30) was used to collect the data regarding attitude towards psychiatry. ATP-30 is a 30 item scale developed by Burra et al which examines attitude towards psychiatry on the basis of a 5-point Likert scale ( $1=$ strongly agree, $5=$ strongly disagree). Questions were designed to cover attitude towards mental illness, psychiatric patients, psychiatrist, psychiatric institutions, teaching, knowledge and career choice. Out of total 30 items, 15 were positively phrased and 15 negatively phrased. A total score was calculated by adding all item scores which ranges between 30 and 150. The higher the score, the more favourable the attitude towards psychiatry. A score of 90 indicates a neutral attitude. Score above 90 indicates positive attitude while score below 90 indicates negative attitude.

\section{RESULTS}

Out of total 45 non-psychiatry consultants, 30 consultants completed the questionnaire giving a response rate of $66.67 \%$.

Table 1: Demographic and career data

\begin{tabular}{|l|l|l|}
\hline & Frequency & Percentage (\%) \\
\hline Age, Years & & \\
\hline $30-45$ & 17 & 56.7 \\
\hline $45-60$ & 6 & 20.0 \\
\hline$>60$ & 7 & 23.3 \\
\hline Total & 30 & 100 \\
\hline Gender & & \\
\hline Male & 27 & 90.0 \\
\hline Female & 3 & 10.0 \\
\hline Total & 30 & 100 \\
\hline Current Designation & & \\
\hline Asst. Prof & 14 & 46.7 \\
\hline Assoc. Prof & 6 & 20.0 \\
\hline Professor & 10 & 33.3 \\
\hline Total & 30 & 100 \\
\hline Total Years of experience & & \\
\hline $0-10$ & 19 & 63.3 \\
\hline $10-20$ & 8 & 26.7 \\
\hline$>20$ & 3 & 10.0 \\
\hline Total & 30 & 100 \\
\hline Experience in psychiatry & & \\
\hline Yes & 10 & 33.3 \\
\hline No & 20 & 66.7 \\
\hline Total & 30 & 100 \\
\hline & & \\
\hline
\end{tabular}


The mean age was $46.46 \pm 13.56$. High majority of the consultants were male $(90.0 \%)$. Looking at the frequency distribution of current designation, $46.7 \%$ of the consultants were Assistant Professor while Associate professors and professors constituted $20 \%$ and $33.3 \%$ respectively. Majority $(63.3 \%)$ of the consultants had upto 10 years of total experience. Significant majority $(66.7 \%)$ of the consultants did not have any experience in psychiatry in their medical career.

The analysis of the ATP-30 showed a mean score of $110.03 \pm$ 12.37 ( minimum 91, maximum 135). Thus indicating a generally positive attitude towards psychiatry. Total ATP-30 score as per each individual is shown in Figure 1.

\section{Figure 1: Total ATP-30 score of each individual consultant}

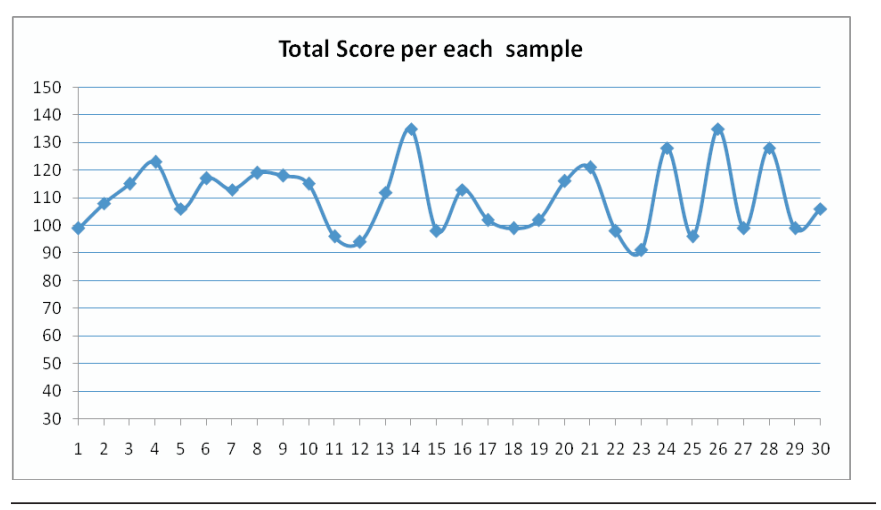

Analyses of the ATP-30 score showed that Professors had the least mean score $(104.9 \pm 9.7)$ as compared to other consultants. Consultants who had a total experience of more than 20 years had the lowest mean ATP-30 Score(104.9 \pm 9.7$)$ as compared to others. Analysis of Mean score with respect to experience in psychiatry showed that, consultants having exposure to psychiatry had a higher mean ATP-30 score (118.2 \pm 13.6$)$ as compared to those who do not have (105.9 \pm 9.7$)$.

There were no significant association between age, gender, designation, total years of experience and ATP-30 scores. However, there was significant association found between experience in psychiatry and total ATP-30 scores $(\mathrm{P}=0.008)$. Details of the correlation is shown in table 2

Table 2: Relationship between age, gender, designation, total years of experience, experience in psychiatry and ATP-30 score

\begin{tabular}{|l|l|l|}
\hline \multirow{2}{*}{\multicolumn{1}{c|}{ Item }} & \multicolumn{2}{c|}{ Total ATP Score } \\
\cline { 2 - 3 } & Correlation & Sig. \\
\hline Age & -.245 & .192 \\
\hline Gender & .109 & .567 \\
\hline Designation \& totalscore & -.235 & .211 \\
\hline Total Years of Experience & -.148 & .434 \\
\hline Experience in Psychiatry & -.475 & .008 \\
\hline
\end{tabular}

Some of the items having significant negative responses are shown in table 3.

Table 3: Some items of ATP-30 questionnaire with the responses obtained

\begin{tabular}{|l|l|l|l|l|}
\hline $\begin{array}{l}\text { Item } \\
\text { No. }\end{array}$ & Questionnaire & $\begin{array}{l}\text { Strongly } \\
\text { Agree/Agree }\end{array}$ & $\begin{array}{l}\text { Neutral } \\
\text { Disagree/Disagree }\end{array}$ \\
\hline 5 & Psychiatrists talk a lot but do very Little & $11(36.67 \%)$ & 4 \\
\hline 7 & $\begin{array}{l}\text { At times it is hard to think of psychiatrists equal to } \\
\text { other doctors }\end{array}$ & $9(30.0 \%)$ & 19 \\
\hline 22 & $\begin{array}{l}\text { Psychiatry is so amorphous that it cannot be taught } \\
\text { effectively }\end{array}$ & $14(46.67 \%)$ & 7 \\
\hline 26 & $\begin{array}{l}\text { Psychiatric treatment causes patients to worry about } \\
\text { symptoms. }\end{array}$ & $15(50.0 \%)$ & 9 \\
\hline 27 & Little that psychiatrist can do for their patients. & $9(30.0 \%)$ & 6 \\
\hline 29 & Psychiatric hospitals little more than prisons & $11(36.67 \%)$ & 6 \\
\hline
\end{tabular}




\section{DISCUSSION}

Mental Health has been hidden behind the curtain of stigma and discrimination for a long time. Not only the mentally ill, even the mental health professionals are stigmatized. ${ }^{13}$

The increasing demand of psychiatrists and psychiatry oriented physicians and surgeons can not be overlooked because of the following reasons: a. Global sociopolitical changes have resulted in significant increase in psychiatric morbidity. ${ }^{14}$ b. According to W.H.O report psychiatric disorders are now among the top ten causes of economic burden ofdiseases while depression alone is second in the list. ${ }^{15}$ c. Concern for management of psychological problems in physically ill patients is increasing. ${ }^{16} \mathrm{~d}$. Literature has shown significant association of psychiatric disorders with physical illness. ${ }^{15,17}$ e. Liaison psychiatry is emerging as a subspecialty. ${ }^{16,17}$

Till now the supply of the manpower in psychiatry could not keep pace with the demand. It is because less attraction in psychiatry has been observed all over the world. Different perceptions have been reported to be responsible for this image problem. The most reported reasons are stigma, stress, the attitude of non-psychiatric faculty and assumed higher rate of psychiatric morbidity in psychiatrists. ${ }^{18-23}$ A study conducted in neighboring country of India in 1988 has also suggested that lack of interest for psychiatry among medical students may be due to insufficient teaching hours, inadequate staff, lack of involvement of senior faculty, absence of provision for examination in the subject, lack of access to audiovisual aids, teaching of psychiatry in mental hospitals and poor planning of curriculum

The main study finding was that non-psychiatry consultants from UCMS have a positive attitude towards psychiatry. Studies in similar population is not done till date. The mean ATP-30 score (110.03) was consistent with the finding in other studies among General Practitioners, Interns by Thompson $\mathrm{C}$ et al, Malhi GS et al, Maidment R et al, McFarland $\mathrm{M}$ et al. ${ }^{9,10,1}$ The positive attitude was independent of age, gender, designation and total years of experience. However, there was strong correlation between total score and experience in psychiatry $(\mathrm{p}=0.008)$. This indicates that even a brief exposure to psychiatry during their medical course/ career is very vital in improving one's attitude towards psychiatry. This finding substantially supports compulsory posting in psychiatry during the medical training so that the attitude towards psychiatry improves and also it helps in dispelling misbeliefs about psychiatry.
It was interesting to know that Professors had lowest mean score (104.9) as compared to other consultants. It might be due to the fact the psychiatry was not that developed in our part of the world during their medical training and also that psychiatry was not a part of the curriculum in the medical training. As expected, consultants who had been exposed to psychiatry for some period of time during their training/career had significantly higher mean score. It warrants that medical professionals has to undergo exposure to psychiatry compulsorily if we want to promote psychiatry as a discipline. The positive attitude seen in the study sample could be because of the well established psychiatry department in the UCMS$\mathrm{TH}$.

\section{LIMITATIONS OFTHE STUDY}

The study has some limitations. Firstly, the sample size was small. It was because of lesser number of full-time consultants working in the hospital. Second limitation of the study is that the ATP-30 questionnaire that was used in this study is actually designed for medical students population. However, the tool has been used in study of general practitioners' attitude to psychiatry because this scale attempts to generate a broader opinion on psychiatry as a discipline.

\section{CONCLUSION}

Majority of the consultants had positive attitude towards psychiatry. However some erroneous beliefs are still prevalent among the consultants. The attitude of non-psychiatry consultants directly/indirectly affects the development of psychiatry as a discipline. Further studies of such kind in a larger scale can help to determine whether changes in attitudes towards psychiatry are needed among the non-psychiatry consultants.

\section{REFERENCES}

1. Jha A. Nepalese psychiatrists' struggle for evolution. Psychiatric Bulletin. 2007, 31:348-50.

2. Singh PM, Vaidya l, Shrestha DM, Tajhya R, Shakya S. Consultation liaison psychiatry at Nepal Medical College and Teaching Hospital. Nepal Med Coll J 2009; 11(4): 272-74.

3. World Health Organization. Investing in mental health. 2003. WHO, Geneva.

4. Nielson AC: (1979) The Magnitude of Declining Psychiatric Career Choice, Journal Medical Education Vol. 54, 632-37.

5. Goldacre MJ, Turner G, Fazel S, Lambert T. Career choices for psychiatry: national surveys of graduates of 1974-2000 from UK medical schools. BrJPsychiatry 2005; 186: 158-64. 
6. Furnham AF. Medical students' beliefs about nine different specialties. Br MedJ(Clin Res Ed) 1986;293(6562):1607-10.

7. Hunt DD. Frequency and effect of negative comments ("badmouthing") on medical students' career choices. Acad Med. 1996;71(6):56-59

8. Rajagopal S, Singh K, Godfrey E. Psychiatry as a career choice compared with other specialties: a survey of medical students. PsychiatricBulletin.2004;28:444-46.

9. Harris C. Medical stereotypes. BMJ 1981; 283: 1676-77.

10. Rezler, AG. (1976). Methods of attitude assessment for medical teachers. Medical Education, 10, 43-51.

11. Baron RA. (1992). Psychology 2nd edn. Allyn \& Bacon, Boston.

12. Kalra G. Talking about stigma towards mental health professionals with psychiatry trainees: a movie club approach. Asian J Psychiatr. 2012 Sep;5(3):266-68.

13. Niaz U, Hassan S, Hussain H, Saeed S. Attitude towards psychiatry in pre-clinical and post-clinical clerkships in different medical colleges of Karachi. Pak J Med Sci 2003;19(14):253-63

14. World Health Organization. Investing in mental health. 2003. WHO, Geneva.

15. Lloyd GG, Mayou RA. Liaison psychiatry or psychological medicine? BrJ Psychiatry 2003;183-87.
16. Farooq S, Akhter J, Anwar E, Ahmed I, Jadoon IU, Khan SA. The attitude and perception of hospital doctors about the management of psychiatric disorders. J Coll Physicians Surg Pak 2005;9(15):552-55.

17. Malhi GS, Parker GB, Parker K, Carr VJ, Kirkby KC, Yellowlees $P$, et al. Attitude toward psychiatry among students entering medical school. Acta Psychiatry Scand 2003;107(6):424-29.

18. Karim R, Nizhar MA. What do the doctors in Lahore think about psychiatry? Annals 1999;5(2):170.

19. Alexender PJ, Kumaraswamy N. Impact of medical school experience on senior medical students' interest in psychiatry. Indian J Psychiat 1995;37(1):31-34.

20. Byrne P. Stigma of mental illness. Changing minds, changing behaviour. Br JPsychiatry 1999; 174:1-2.

21. Caplon RP. Stress, anxiety and depression in hospital consultants, general practionners and senior health service managers. BMJ 1994;309:1261-63.

22. Rich CL, Pitts FN Jr. Suicide by psychiatrists: a study of medical specialists among 18,730 consecutive physician deaths during a fiveyear period, 196772. J Clin Psychol 1980;41:261-63

23. Bhaskaran K. Undergraduate psychiatric education. India J Psychological Med 198;11:51-55. 